\title{
The impact of a school-based health education programme on knowledge regarding risk factors for chronic diseases of lifestyle: A pilot study
}

\author{
J.M. FRANTZ \\ Department of Physiotherapy, University of the Western Cape, Private Bag X17, Bellville 7530, \\ Cape Town, South Africa.E-Mail: jfrantz@uwc.ac.za
}

\begin{abstract}
The aim of this study was to evaluate the effectiveness of a health education programme on the risk factors of chronic diseases of lifestyle. This study adopted a one-group pretest posttest nonexperimental design. The study sample consisted of 93 grade 8 and 9 learners at a high school in the Western Cape, South Africa. The intervention was a 5-week health education programme that aimed at improving knowledge regarding the risk factors for chronic diseases of lifestyle. The intervention included lectures, research and presentations. Data were analysed descriptively and inferential statistics were analysed to determine associations between variables. The pre-test questionnaire reported learners to have achieved low scores on the areas of diabetes and stroke but after the intervention there was a significant improvement $(p<0.05)$. There is need to design and incorporate specific health education programmes within the school setting that will create an awareness among the youth as this is the most at-risk group to indulge in health risk behaviour. It is important to design interventions that are specific to the target population. This programme may be a step in teaching young people to identify risk factors of chronic diseases of lifestyle and also assist them to implement effective preventive measures.
\end{abstract}

Keywords: Learners, risk factors, chronic diseases.

How to cite this article:

Frantz, J.M. (2011). The impact of a school-based health education programme on knowledge regarding risk factors for chronic diseases of lifestyle: A pilot study. African Journal for Physical, Health Education, Recreation and Dance, June (Supplement), 70-81.

\section{Introduction}

Currently all public schools in South Africa have to adjust to the challenge of decreased curriculum time for health and physical education. In contrast to this, schools are required to meet the needs of a society which is facing an increase in chronic diseases of lifestyle. School-based education programmes are important as they provide the learners with the skills and knowledge that will enable them to make informed health decisions that are best for them. Successful planning of school health education programmes should also include stakeholders such as community members and parents, besides the learners and teachers. Together the community, tertiary institutions and schools can develop school health education programmes that reflect the culture of the community and that are sensitive to the needs of the child. 


\section{Frantz}

Risk factors of chronic diseases of lifestyle have been on the increase in South African communities, especially among adolescents (Frantz, 2006). This trend is of concern to health professionals as these risk factors contribute to some of the leading causes of death, including cardiovascular disease and cancer. Increasingly, this trend is evident among adolescents and, as a result, healthy lifestyle practice needs to be nurtured from an early age. Chronic diseases such as hypertension, stroke and diabetes require patient education in order to achieve adequate control and to prevent adverse health outcomes (Williams et al.,1998). In addition, research has also demonstrated that health professionals could use theoretically based teaching strategies to encourage behaviour change (Cooper et al., 2001). According to Samsa et al. (1997), hypertensive subjects tend to be aware of their increased risk for stroke, which is connected to better compliance in stroke prevention practices. However, patients at risk of cerebrovascular disease tend to underestimate their risk, especially if they are currently without symptoms and lack direct experience with the condition. Consequently, Samal et al. (2007) suggested that there is a need to improve knowledge and awareness of cerebrovascular disease in people who are at increased risk. School children are considered to be an important target group for health education activities with the underlying objective of encouraging healthy lifestyles. This is a target group with increasing risk for chronic diseases and little awareness of this risk as they often participate in health risk behaviours. Schools in South Africa have included a life orientation module as part of their curriculum, which includes a section on health and health promotion. Integrating an effective health education programme with the life orientation programme that was focused at the level of the adolescent was considered, bearing in mind factors influencing education, curriculum development strategies and education delivery styles. This integration of a health education programme in the current curriculum was discussed and consensus regarding the content was reached among key stakeholders such as life orientation teachers, school principals and members of the Western Cape Department of Education. Thus the aim of the current study was to determine the impact of school based health education programme on knowledge regarding the risk factors for chronic diseases of lifestyle.

\section{Materials and Methods}

The study was conducted among 120 grades 11 and 12 learners in the Western Cape who were aged 15-18 years. All learners were invited to participate in the study. Of these, 50 and 70 were grades 12 and 11 learners, respectively. Permission to carry out the study was obtained from the University of the Western Cape ethics committee, as well as the Western Cape Department of Education. Written informed consent was obtained from the school principal on behalf of the parents and assent from each pupil who participated in the study. 
This study adopted a one-group, pre-test post-test non-experimental design. Though this design reportedly has low internal validity, it was still appropriate in this study since the primary focus was to test content of the programme and its baseline impact on knowledge in a preliminary manner. A pre-test questionnaire testing the knowledge of learners regarding risk factors of CDL was done prior to the intervention and one week thereafter. The health education programme ran for a period of 5 weeks with a 40-minute session once a week as part of the life orientation programme of each specific grade. The specific outcomes of the programme were to allow the participants to develop knowledge relating to the concept of chronic diseases of lifestyle and its risk factors; to personally interact with someone with, or a case related to, chronic diseases of lifestyle and to allow the learner to identify personal risk factors present in their own lives. In addition, the programme allowed the learner to design a presentation or poster on the disease and risk factors and demonstrate the ability to share knowledge gained in a formal setting. Within the programme, basic information regarding CDL was discussed. Risk factors for the chronic diseases were presented in a case- based format and learners had to identify the presence of the risk factors and possible modifiable lifestyle behaviours. The programme was implemented by health profession students who had a background in health promotion strategies as part of their clinical rotation and thus did not interfere with the educational programme of the teachers. The health education programme was designed to include full participation of the learners and allowed for the learners to research some information and share it with others. In addition, it was hoped that learners would be able to use the knowledge gained to make informed decisions regarding personal and community health as it relates to chronic diseases of lifestyle. Table 1 provides an outline of the health education programme presented over the five-week period.

\section{Instrument}

The Knowledge on Risk Factors for CDL questionnaire (Frantz, 2008) was used for pre and post test measures. Acceptable psychometric properties were reported (Chronbachs alpha of 0.8) indicating appropriateness for use in a South African sample (Frantz, 2008). The knowledge questionnaire related to questions on hypertension, diabetes and stroke and the respondents could obtain a maximum score of 5,11 and 10, respectively with a total score of 26 correct answers.

\section{Data Analysis}

Knowledge scores were categorized into three sections namely poor knowledge $(<50 \%)$; average knowledge (51-70\%) and good knowledge $(>70 \%)$. Data were analysed descriptively using frequencies and cross tabulations. In addition, Chisquare test was performed to determine associations between the independent and dependent variables using frequency data. 
Table 1: Outline of the health education programme

\begin{tabular}{|c|c|c|c|}
\hline Week & Objective & Content & Activities \\
\hline 1 & $\begin{array}{l}\text { Provide an } \\
\text { overview of } \\
\text { chronic diseases } \\
\text { of lifestyle }\end{array}$ & $\begin{array}{l}\text { Risk factors and health risk behaviour } \\
\text { as they relate to chronic diseases of } \\
\text { lifestyle }\end{array}$ & $\begin{array}{l}\text { Knowledge questionnaire } \\
\text { for learners } \\
\text { Powerpoint presentation } \\
\text { with information }\end{array}$ \\
\hline 2 & $\begin{array}{l}\text { Identifying } \\
\text { personal risk } \\
\text { factors as it } \\
\text { relates to CDL }\end{array}$ & $\begin{array}{l}\text { Learner interaction with a case study } \\
\text { relating to risk factors for diabetes, } \\
\text { hypertension and stroke. }\end{array}$ & $\begin{array}{l}\text { Case studies based on the } \\
\text { information provided in } \\
\text { powerpoint. } \\
\text { Questionnaire identifying } \\
\text { own health risk behaviours }\end{array}$ \\
\hline 3 & $\begin{array}{l}\text { Evaluate and } \\
\text { research } \\
\text { information } \\
\text { relating to CDL } \\
\text { identified }\end{array}$ & $\begin{array}{l}\text { Research material and pictures used to } \\
\text { make a poster to highlight the risk } \\
\text { factors for chronic diseases of lifestyle }\end{array}$ & $\begin{array}{l}\text { Learners research one of } \\
\text { the conditions and make a } \\
\text { poster summarizing all the } \\
\text { information found (small } \\
\text { groups) }\end{array}$ \\
\hline 4 & Design a poster & Share information gathered & Learners present posters \\
\hline 5 & $\begin{array}{l}\text { Recap and } \\
\text { evaluate } \\
\text { knowledge }\end{array}$ & Evaluate knowledge & $\begin{array}{l}\text { Knowledge questionnaire } \\
\text { repeated and learners } \\
\text { identify a project for their } \\
\text { community }\end{array}$ \\
\hline
\end{tabular}

\section{Results}

Of the 120 questionnaires that were distributed, 93 were returned yielding a return rate of $77.5 \%$ in total, with $74 \%(52 / 70)$ return rate for grade 11 and $82 \%$ $(41 / 50)$ for grade 12 . Of the participants in the study, $64.5 \%$ were females and $35.5 \%$ males. The mean age among the participants was 15.6 years $(\mathrm{SD}=0.7)$. Table 2 illustrates how many of the participants had heard about CDL and its associated risk factors.

Determining the risk factors present in the current sample yielded the information presented in Figure 1, which indicates that $35 \%$ of the learners smoked, $81 \%$ drank alcohol, $59 \%$ were physically inactive and $24 \%$ did not have breakfast and lunch daily. From the results obtained, it was found that a significant $(\mathrm{p}<.05)$ amount of learners started smoking and drinking at ages $10-$ 13 years.

Table 3 highlights the number of correct answers per question before and after the health education programme as well as the average scores obtained per section. The overall results of the pre-test knowledge questionnaire yielded a mean score of $13.08 \pm 3.48$ and a range of 5-21. Following the health education 
Table 2: Information on chronic diseases of lifestyle

\begin{tabular}{llll}
\hline Variable & & Number & Percentage \\
\hline Heard of CDL & Yes & 49 & 52.7 \\
Heard of stroke & No & 44 & 47.3 \\
Heard of hypertension & Yes & 82 & 88.2 \\
& No & 11 & 11.8 \\
Heard of diabetes & No & 56 & 60.2 \\
Which factors contribute to & Yes & 43 & 39.8 \\
CDL & So & 85 & 91.4 \\
& Phoking & 8 & 8.6 \\
& Pousical activity & 69 & 74.2 \\
& Obesity & 13 & 14.0 \\
& Alcohol & 16 & 17.2 \\
& Stress & 50 & 53.8 \\
& Balanced Diet & 65 & 69.9 \\
Can CDL be prevented & Medication & 81 & 87.1 \\
& Yes & 13 & 22.6 \\
& No & 64 & 14.0 \\
Have you been taught in & I don't know & 25 & 68.8 \\
school about CDL & Yes & 4 & 26.9 \\
\hline
\end{tabular}

$\mathrm{CDL}=$ Chronic Diseases of Lifestyle

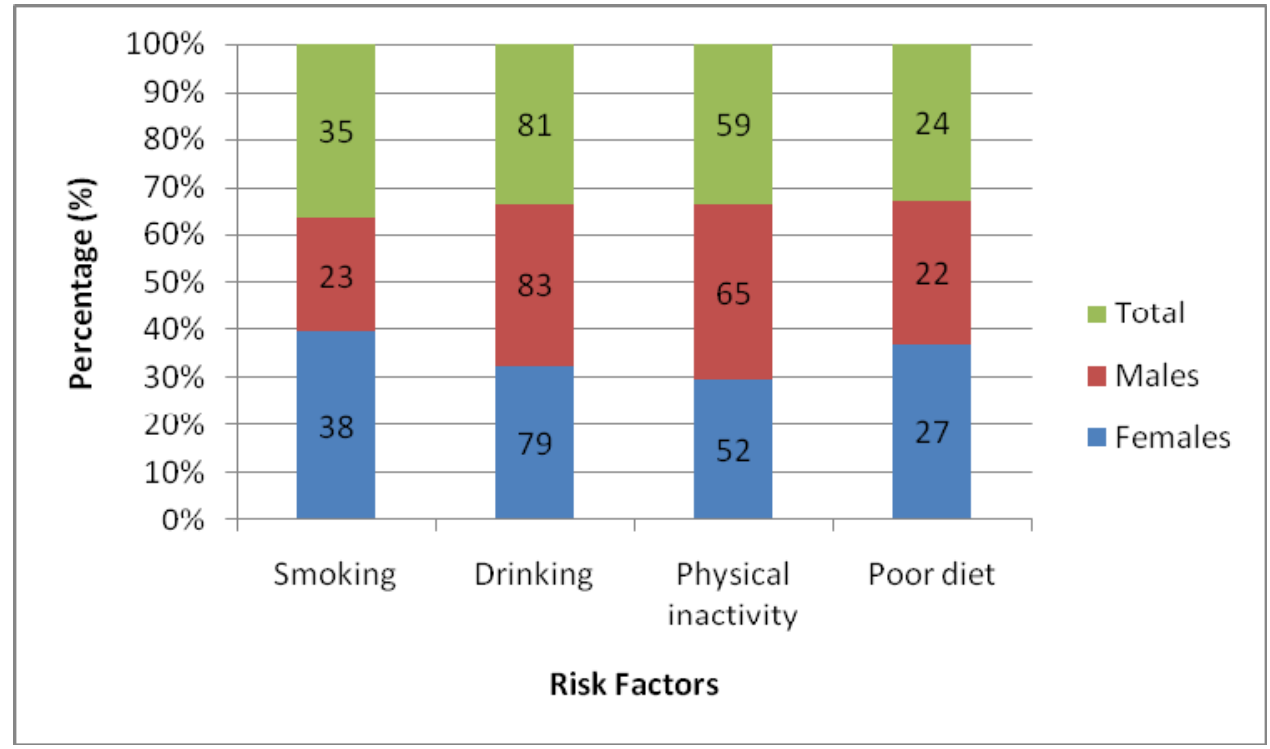

Figure 1: Presence of risk factors among learners 
programme the mean and range of the overall score were $18.91 \pm 3.69$ and a range of 5-24, respectively. Statistically, the post-test score (18.9) was significantly higher $(\mathrm{p}<0.05)$ than the pre-test score $(13.08)$ suggesting that knowledge of CDL increased significantly.

Table 3: Responses to knowledge risk factors for chronic diseases of lifestyle questionnaire

\begin{tabular}{llll}
\hline \multicolumn{1}{c}{ Question } & \multicolumn{2}{c}{ No. of correct responses (\%) } & Average Score: Mean (SD) \\
\hline Hypertension & Pre & Post & Pre: \\
1 & 17.2 & 94.6 & $2.46(1.13)$ \\
2 & 16.1 & 60.2 & Post: \\
3 & 19.4 & 87.1 & $3.64(0.95)$ \\
4 & 20.4 & 83.8 & \\
5 & 57.0 & 40.1 & Pre: \\
Diabetes & Pre: & Post: & $4.97(1.7)$ \\
1 & 6.5 & 95.7 & \\
2 & 86.0 & 24.7 & Post: \\
3 & 30.1 & 66.7 & $7.49(1.85)$ \\
4 & 21.5 & 65.6 & \\
5 & 14.0 & 91.4 & \\
6 & 68.8 & 52.7 & \\
7 & 63.4 & 72.0 & \\
8 & 50.5 & 72.0 & \\
9 & 19.4 & 56.9 & \\
10 & 63.4 & 90.3 & Pre: \\
11 & 63.4 & 58.1 & $5.64(1.92)$ \\
Stroke & Pre: & Post: & Post: \\
1 & 19.4 & 91.4 & $7.77(1.85)$ \\
2 & 69.9 & 84.9 & \\
3 & 20.4 & 84.9 & \\
4 & 43.0 & 52.9 & \\
5 & 40.9 & 69.0 & \\
6 & 36.6 & 54.8 & \\
7 & 8.6 & 87.1 & \\
8 & 36.6 & 80.6 & \\
9 & 37.6 & 81.7 & \\
10 & 43.0 & 81.7 & \\
\hline & & & \\
\hline & & & \\
\hline
\end{tabular}

Figure 2 illustrates the difference in classification of scores for each section. Of the responses, $41 \%$ of the learners obtained overall scores of less than $50 \%, 41 \%$ obtained overall scores of $51-70 \%$ and $18 \%$ obtained overall scores above $70 \%$. More female learners (25\%) scored above $70 \%$ on the overall score compared to the male learners $(18 \%)$. Of the total responses received after the health education programme, $7.5 \%$ of the learners scored below $50 \%, 15.5 \%$ scored between 51 and $70 \%$ and $77.4 \%$ scored above $70 \%$. 


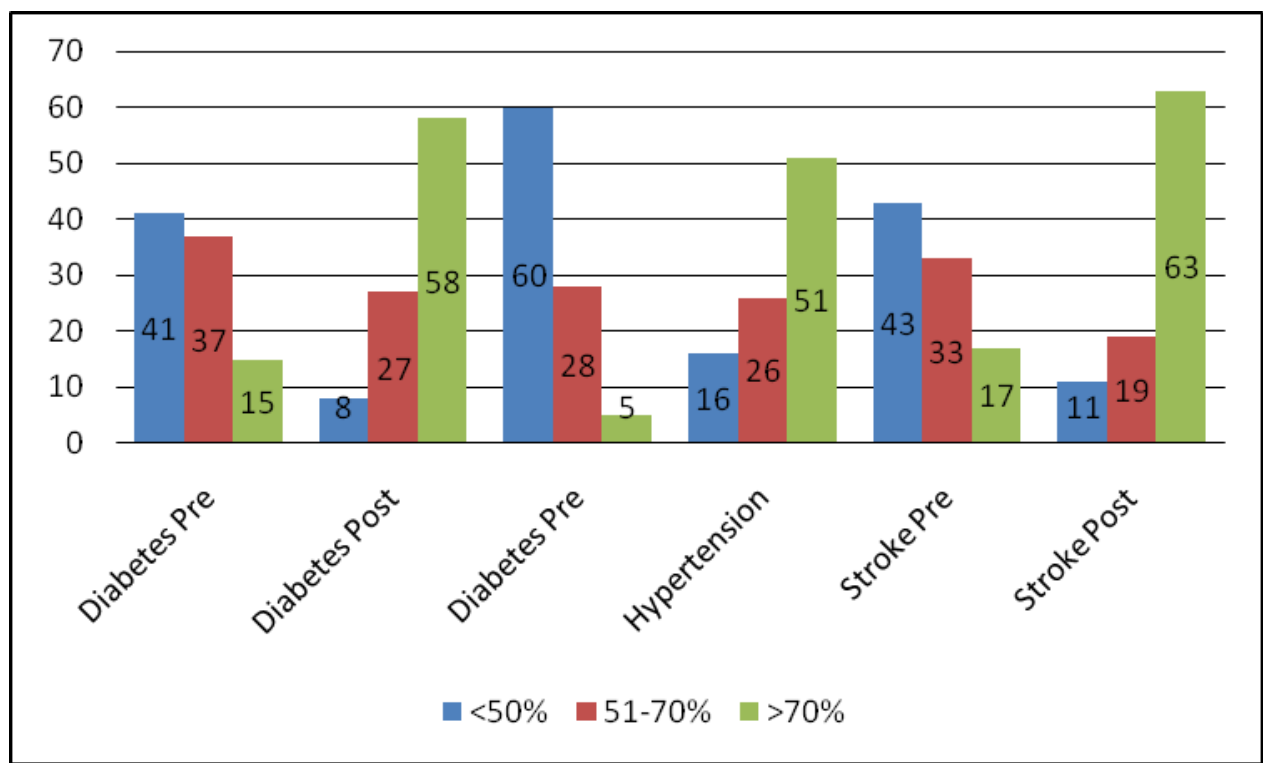

Figure 2: Knowledge of risk factors for chronic diseases of lifestyle before and after intervention

Projects identified for the community included a health awareness day for the youth at the pilot school and for the elderly in the community. In addition, learners highlighted the need to share health information with their family members.

\section{Discussion}

According to Botvin, Schinke and Orlandi (1995), intervention programmes generally attempt to influence factors relating to behavioural change. This study showed that positive health education information relating to knowledge concerning CDL risk factors increased learners' awareness of the risk factors. This intervention programme was specifically focused on high school learners and had a specific purpose. Elkin (1999) argued that many intervention programmes focusing on adolescents and youth tend to be general and need to be more specific, targeting specific group with a specific goal in mind.

However, one of the challenges facing health education programmes is the translation of the information learnt into behavioural change. This is a major concern but as highlighted by Blum (1998), the role of health professionals in the public sector as it relates to adolescent health is to "inform and educate the public". Blum (1998) emphasizes that this process of informing and educating the public is our advocacy function. However, the challenge is whether to stop at the information and education stage or attempt to influence actual behavioural change. Thus there is need to evaluate if these health education programmes are successful in changing behavior and assess the areas that need improvement. 
In the present study, the process of identifying risk factors within themselves, researching the problem and ultimately sharing the information assisted in raising awareness in the group. In addition, participants were able to apply their knowledge to case studies as well as produce a psycho-educative learning tool. Wills et al. (2008) suggested the need for youth involvement in identifying strategies for their own health.

Evaluating general public awareness of disease can help to improve public information programmes about diseases such as stroke, hypertension and diabetes. Park et al. (2006) confirmed the need for more public education around stroke, targeted particularly at those who are less educated and currently unaware of the details of the condition. The authors indicated that education should include information about risk factors, warning symptoms and the methods used to prevent and manage diseases such as stroke. The current study aimed to improve the knowledge of learners between the ages of 15 and 18 years as it relates to CDL risk factors and initiate them into methods of disseminating information to others. The results indicated that the basic information provided in the health education programme assisted the learners to inculcate and recall health knowledge over a short period.

\section{Conclusion}

There is a need to design and incorporate specific health education programmes within the school setting that will create awareness of the prevalence of CDL risk factors among the youth. It is however important to design interventions that are specific to the target population. This current programme is an example of how young people could be taught to identify CDL risk factors and implementing effective preventive measures. However, it would be important to determine the sustainability of knowledge use among the youth in the long term.

\section{Acknowledgement}

The author thanks the Western Cape Education Department (WCED) for granting permission to conduct this study. The support received from all the teachers, principals, learners and parents in carrying out this study is gratefully acknowledged. This material is based upon work supported by the National Research Foundation. Any opinion, findings and conclusions or recommendations expressed in this article are those of the author and therefore the NRF does not accept any liability regarding the content of the work.

\section{References}

Blum, R. (1998). Improving the health of youth: A community health perspective. Journal of Adolescent Health, 23(5), 254-258. 
Botvin, G., Schinke, S. \& Orlandi, M. (1995). School based health promotion: substance abuse and sexual behavior. Applied and Preventive Psychology, 4, 167-184.

Cooper, H., Booth, K., Fear, S. \& Gill, G. (2001) Lessons from chronic disease patient education. Patient Education and Counselling, 44, 107-117.

Elkin, T. (1999). Health Promotion Interventions in Adolescents: Different Populations, different approaches. Cognitive and Behavioural Practice, 6, 127-128.

Frantz, J.M. (2006). Physical inactivity as a chronic disease risk factor among high school learners in public schools in a local community in South Africa. South African Journal of Research in Sport and Physical Education, 28(2), 73-80.

Frantz, J.M. (2008). A knowledge assessment questionnaire relating to risk factors for chronic disease of lifestyle for high school learners: validity and reliability issues. Journal of Community and Health Sciences, 3(1), 30-37.

Park, M., Jo, S., Jo, I., Kim, E., Eun, S., Han, C. \& Park, M. (2006). No difference in stroke knowledge between Korean adherents to traditional and western medicine - the AGE study: An epidemiological study. BioMed Central Public Health, 6(153).

Samal, D., Greisenegger, S., Auff, E., Lang, W. \& Laloscheck, W. (2007). The relation between knowledge about hypertension and education in hospitalized patients with stroke in Vienna. Stroke, 38, 1304-1308

Samsa, G., Cohen, S., Goldstein, L., Bonito, A., Duncan, P., Enarson, C., DeFriese, G., Horner, R. \& Matchar, D. (1997). Knowledge of risk among patients at increased risk for stroke. Stroke, $28,916-921$.

Williams, M., Baker, D., Parker, R. \& Nurss, J. (1998). Relationship of functional health literacy to patient's knowledge of their chronic disease. Archives Internal Medicine, 158,166-172.

Wills, W., Appleton, J., Magnusson, J. \& Brooks, F. (2008). Exploring the limitations of an adult-led agenda for understanding the health behaviours of young people. Health and Social Care in the Community, 16 (3), 244-252 